Vol. 3, No. 2 | July - December 2020

\title{
Experimental Analysis of Lead Acid Battery by Introducing Graphene \& Lead Composite
}

\author{
Muhammad Atif Qaimkhani ${ }^{1}$, Saifullah Samo ${ }^{1}$, Shakeel Ahmed Shaikh ${ }^{1}$, Tanweer \\ Hussain $^{1}$
}

\begin{abstract}
:
In this paper, an experimental analysis of grid material for a lead acid battery is presented, where graphene is introduced in lead by using powder metallurgy technique. In proposed composite, the graphene is added to grid material of lead acid battery to increase battery life cycle, performance, charge acceptance rate. Four lead-graphene composite specimen of different composition are developed, for performing the series of tests to analyze charge acceptance rate. of lead acid battery. The graphene and lead are used with different percentage ratios, a good percentage of the graphene is found between the $0.5 \%$ to $2.0 \%$. Experimental result shows the effectiveness of composites prepared. The results obtained also compare with the spongy lead which is being normally used in lead acid batteries.
\end{abstract}

\section{Keywords: energy storage devices, energy storage materials, Graphene, Lead acid battery}

\section{Introduction}

Potential use of graphene is the thinnest material and has a potential use in different daily life applications is in increasing. It is a hexagonal two-dimensional lattice, made of a single layer of bonded carbon atoms. Defect free, single crystalline graphene possess the highest strength and exhibits unique mechanical, electrical and thermal properties [1-5]. The lead is a heavy metal with greater density as compared to graphene. Graphene is a best candidate for electrode material to store the energy.

As, there are different sources to generate electric energy. The search is still going on to replace the non-renewable sources with renewable sources to generate the electric energy. Wind turbines and solar panels are good example of renewable sources, but these sources are not available 24/7 and vary from seconds to hours and days [6]. Therefore, storing of electrical energy is required to overcome the intermittency. It is important that the battery should be reliable and capable of delivering required power and energy when required. Battery is a series of cells and can be used to store electrical energy. Different combinations of materials can be used to manufacture cells, examples are SodiumSulphur (NaS), nickel-cadmium (NiCd), Lithium polymer (Li-ion polymer), lead-acid $(\mathrm{Pb})$, and Lithium-ion (Li-ion) [7-9]. There are different selection criteria for battery, like life cycle, depth of discharge robustness, power density, cost, temperature, and so on [10-11]. Besides traditional use of lead acid batteries in electric vehicles, load leveling, and solar energy storage has been observed, this new trend demands certain challenges in the design

${ }^{1}$ Mehran University of Engineering \& Technology, Jamshoro, 76090, Sindh, Pakistan

Corresponding Author: tanweer.hussain@ faculty.muet.edu.pk 
too. Charge acceptance rate is one of those challenges.

The main problems with the rechargeable batteries are sulfation of electrolyte, stratification of electrolyte, electrode corrosion and non-cohesion of dynamic mass. These failures lead to decrease in life cycle, performance, charge acceptance rate etc. of rechargeable batteries. This research focused to increase charge acceptance rate of the grid material that indirectly leads to increase life cycle and performance of lead acid batteries, by using graphene. Phosphoric corrosive, the most every now and again considered electrolytic added substance, with positive and negative consequences for battery performance [12]. H3PO4 was found to decrease sulfation, particularly after profound release [13], increment the battery cycle life [14] and back off self-release [15]. The genuine disservice of expansion of H3PO4 was observed to be a misfortune in cell limit [16]. The impact of H3PO4 on the effectiveness of arrangement of $\mathrm{PbO} 2$ on positive- framework amid charging was noticed to rely upon the charging constraints. Citrus extract as an electrolytic added substance was accounted for to diminish oneself release of lead-corrosive batteries by the concealment of $\mathrm{PbO} 2$ reduction [17].

Whenever, the amount of electrolyte and water increases more than maximum rate, chemical reaction takes place and reacts with lead and other metals in the battery. Which can cause sulfation and damage internal parts of battery, because of corrosion charge rate decrease and battery can discharge at very short amount of time. Sulfate affects the charging cycle, results longer charging times and incomplete charging with higher battery temperature $[18,19]$. The low energy density and slow charging are major drawback of lead acid batteries [20]. The configuration of battery grid can also improve the efficiency [21].

The aim of research is to increase the charge acceptance rate, enhance life cycle \& improve efficiency of lead acid battery by using a such enormous material that is graphene. Present experimental analysis is focused on contribution in greening the environment. Some percentile of graphene is introduced in lead by powder metallurgy techniques, which is used as grid material. Graphene is an allotropic form of carbon and has properties of super conductor it does not participate in the reaction but only protect from the corrosion and reduce the resistance between the spongy lead and sulfuric acid. In this study two approaches are applied experimental approach as well as analytical approach to achieve improvement in the lead acid battery.

\section{Specimen Preparation}

The powder-metallurgy process comprises of 4 essential steps: (1) Powder Fabrication (2) Mixing (Blending) (3) Compaction (4) Sintering.

The first step of Powder Metallurgy is powder manufacturing as shown in Fig. 1. It involves preparing, characterizing, and treating material powder which may have solid stimulus on the quality of the final finished product. The size of powder particles normally ranges from 1-100 $\mu \mathrm{m}$, preferably $10-20 \mu \mathrm{m}$. Fig. 2 shows the Powder blending and compaction. Mixing grants consistency in states of the powder particles and facilitates mixing of various powders particles to enhance physical properties.

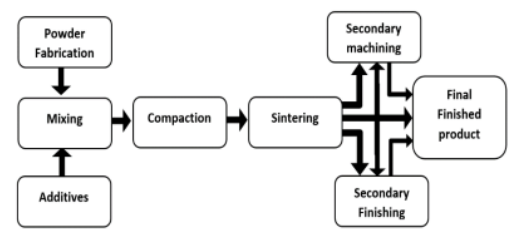

Fig. 1. General procedure of powder metallurgy method. 


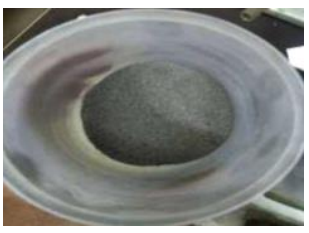

(a)

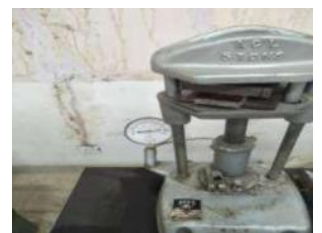

(b)
Fig. 2. (a) Powder Blending (b) Powder Compaction.

Lubricants can be added to amid mixing to enhance the stream and lessen the contact among powder and bites the dust. Binders can be added to enhance the green quality of material amid compaction process. The compaction pressure ranges between 3 to 120 tons/in ${ }^{2}$. The compaction exercise reduces empty space, enhances density, and produce grip and bonding between powder particles to enhance strength. The sintering process is used to convert powder into finished parts, it compacted in a furnace to a temperature below the highest melting point from the constituents.

In this study solid state sintering was used to increase the high strength for that the sintering temperature was set at $229^{\circ} \mathrm{C}$ which is $69.92 \%$ of the melting point of lead and let them further covering all area of the sample for an hour in a controlled furnace and later on slow cooling of specimen done by natural air. After processing all basic steps of powder metallurgy, the final product is shown in Fig. 3 , needed no further machining.

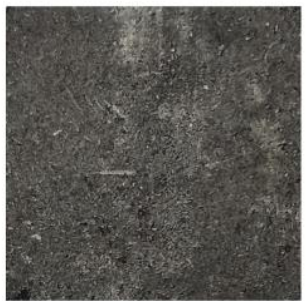

Fig. 3. Final product / Finished Specimen.

Specimens of same size and shape with varying compositions were developed as per data given in table-1. Electrical properties and their difference have been noted of every sample by same procedure. These samples are varied in thickness and in percentage of materials used in composite. Electrical resistivity and conductivity have been carried out.

\section{Experimental Analysis:}

The four specimens of composites were developed with different composition of lead and graphene. Electrical properties and their difference have been noted of each specimen. A series of tests are conducted to analyze the charge acceptance rate of lead acid battery. Such tests include electrical resistivity, cyclic voltammetry, electrical conductivity, Impedance spectra, cyclic voltammetry, Energy dispersive x-ray spectrometer, Scanning electron microscopy, Microstructure, Corrosion test \& charge potential.

TABLE I. Specimen Characteristics

\begin{tabular}{|c|c|c|c|c|c|c|c|}
\hline Sr.\# & Composition $(\%)$ & $\begin{array}{c}\text { Lengt } \\
\mathrm{h} \\
(\mathrm{m})\end{array}$ & $\begin{array}{c}\text { Width } \\
(\mathrm{m})\end{array}$ & $\begin{array}{c}\text { Area } \\
\left(\mathrm{m}^{2}\right)\end{array}$ & $\begin{array}{c}\text { Resistance } \\
(\Omega)\end{array}$ & $\begin{array}{c}\text { Electrical } \\
\text { Resistivity } \\
(\Omega * \mathrm{~m})\end{array}$ & $\begin{array}{c}\text { Electric } \\
\text { al } \\
\text { Conduc } \\
\text { tance } \\
(\mathrm{s} / \mathrm{m})\end{array}$ \\
\hline 1 & $\begin{array}{c}\text { Lead }=99.5 \\
\text { Graphene }=0.5\end{array}$ & 0.054 & 0.054 & 0.002916 & 1.7 & 0.0918 & $\begin{array}{c}10.893 \\
2\end{array}$ \\
\hline 2 & $\begin{array}{c}\text { Lead }=99.0 \\
\text { Graphene }=1.0\end{array}$ & 0.054 & 0.054 & 0.002916 & 1.5 & 0.081 & 12.346 \\
\hline 3 & $\begin{array}{c}\text { Lead }=98.5 \\
\text { Graphene }=1.5\end{array}$ & 0.054 & 0.054 & 0.002916 & 1.5 & 0.081 & 12.346 \\
\hline 4 & $\begin{array}{c}\text { Lead }=98.0 \\
\text { Graphene }=2.0\end{array}$ & 0.054 & 0.054 & 0.002916 & 1.7 & 0.0918 & $\begin{array}{c}10.893 \\
2\end{array}$ \\
\hline
\end{tabular}




\subsection{Microstructure test:}

Microstructure test has been carried on Metallurgical Microscope at Laboratory of Metallurgy \& Materials Engineering department laboratory, in which $2 \%$ etchant of natal added on the surface of each sample after grinding the samples at 2000 waterproof paper. This test shows proper mixing of both materials, surface of samples is tested and verified, which give us optimum results that these materials are added and bounded properly or not.

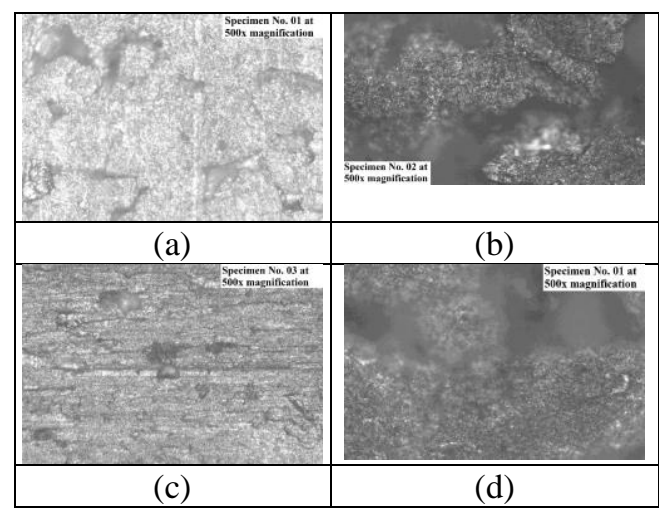

Fig. 4. (a) graphene is $0.5 \%$ and lead is $99.5 \%$. (b) graphene is $1.0 \%$ and lead is $99 \%$. (c) Graphene is $1.5 \%$ and lead is $98.5 \%$. (d) graphene is $2 \%$ and lead is $98 \%$.

Fig. 4 for each samples at 500 zoom extent shows the granular structure of both materials. In Fig. 4 (a) the composition percentage of graphene is $0.5 \%$ whereas the percentage of lead is $99.5 \%$. The magnification of this figure is 500x zoom and analyze material structure on the surface of the composite. Dark grey color shows the presence of graphene whereas white color shows lead. From the Fig. 4(a) it is noted that at some points graphene is not properly mixed and that made bulk of graphene is there instead of granular structure shown in dark gray color. At these points current density is high, but chances of disintegration are also high. In Fig. 4(b) the composition percentage of graphene is $1.0 \%$ whereas the percentage of lead is $99.0 \%$. The magnification of this figure is $500 x$. It is shown in the Fig. 4(b) that mixing of both materials is not equal because most of the graphene is not mixed properly with lead. It is also noted that $99 \%$ of lead is mixed with minimum of amount of graphene. Whereas the excess amount of graphene can dispute easily in open atmosphere. In Fig. 4(c) the composition percentage of graphene is $1.5 \%$ whereas the percentage of lead is $98.5 \%$ and the magnification of this figure is 500x. the Fig. 4(c) shows the proper mixing of both materials all over the surface. This proper mixing can withstand with high conductivity and no powder can dispatch or dilute with acid. In Fig. 4(d) the composition percentage of graphene is $2.0 \%$ whereas the percentage of lead is $98 \%$. The magnification of this figure is 500x. The Fig. 4 (d) shows that excess amount of graphene is not mixed properly with lead. It concludes that this sample can easily break down if high flow of charge or applied voltage high.

\subsection{Charge potential test:}

Charge potential test was carried out in the electrical of engineering department laboratory, by using DC power supply SPS1820 in which material is placed between the electrodes and vary the voltage ranges from $0.7 \mathrm{~V}$ to $2.2 \mathrm{~V}$ and observing that how much current can easily pass from these voltage ranges. Observation table readings which collect from this test are given in Table 2 and graphs in Fig. 5 to Fig. 8 are plotted based on these results. 
Muhammad Atif Qaimkhani (et al.), Experimental Analysis of Lead Acid Battery by Introducing Graphene \& Lead Composite

(pp. 1 - 12)

TABLE II. Specimen Characteristics

\begin{tabular}{|c|c|c|c|c|c|c|c|}
\hline $\begin{array}{c}\text { Specimen No:01 } \\
\text { Pb=99.5\% } \\
\text { C=0.5\% }\end{array}$ & \multicolumn{2}{c|}{$\begin{array}{c}\text { Specimen No:02 } \\
\text { Pb=99\% } \\
\text { C=1.0\% }\end{array}$} & \multicolumn{2}{c|}{$\begin{array}{c}\text { Specimen No:03 } \\
\text { Pb=98.5\% } \\
\text { C=1.5\% }\end{array}$} & \multicolumn{2}{c|}{$\begin{array}{c}\text { Specimen No:04 } \\
\text { Pb=98.0\% C=2.0\% }\end{array}$} \\
\hline $\begin{array}{c}\text { Voltage } \\
\text { (V) Volt }\end{array}$ & $\begin{array}{c}\text { Current } \\
\text { (I)Amp: }\end{array}$ & $\begin{array}{c}\text { Voltage } \\
\text { (V) Volt }\end{array}$ & $\begin{array}{c}\text { Current } \\
\text { (I)Amp: }\end{array}$ & $\begin{array}{c}\text { Voltage } \\
\text { (V)Volt }\end{array}$ & $\begin{array}{c}\text { Current } \\
\text { (I)Amp: }\end{array}$ & $\begin{array}{c}\text { Voltage } \\
\text { (V)Volt }\end{array}$ & $\begin{array}{c}\text { Current } \\
\text { (I)Amp: }\end{array}$ \\
\hline 0.82 & 7 & 0.70 & 4.2 & 0.73 & 10 & 0.82 & 4.9 \\
\hline 1.0 & 9 & 0.96 & 6 & 0.82 & 12.9 & 1.0 & 6.2 \\
\hline 1.23 & 12.0 & 1.0 & 6 & 1.05 & 16 & 1.25 & 12.6 \\
\hline 1.41 & 15.0 & 1.20 & 8 & 1.20 & 17.7 & 1.47 & 17.0 \\
\hline 1.60 & 15.7 & 1.46 & 10 & 1.42 & 17.8 & 1.63 & 17.2 \\
\hline 1.80 & 18.0 & 1.66 & 11.8 & 1.62 & 18.1 & 1.82 & 17.7 \\
\hline 2.0 & 19 & 1.82 & 16 & 1.84 & 18.3 & 2.05 & 20.0 \\
\hline
\end{tabular}

perform work on these electric potential

In Table 2 these current and voltage values shall measure from the D-C power supply to
find out that how much lead acid battery will ranges. By keeping the constant range of voltage for every sample, variation in current is noted.

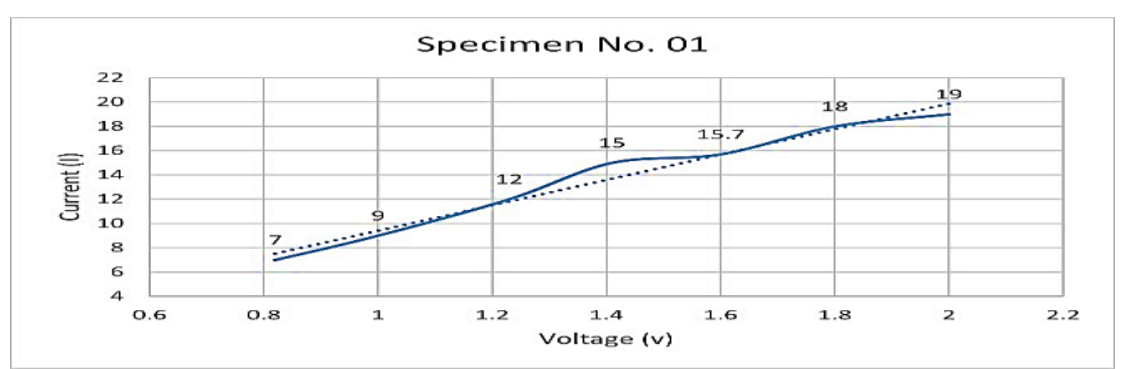

Fig. 5. The composition of graphene material is $2.0 \%$ and lead is $98.0 \%$.

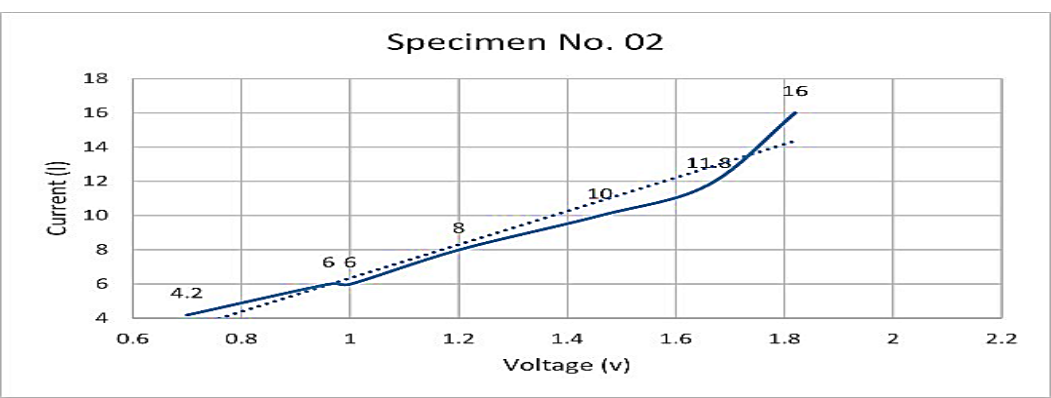

Fig. 6. the composition of graphene material is $1.0 \%$ and lead is $99.0 \%$. 
Muhammad Atif Qaimkhani (et al.), Experimental Analysis of Lead Acid Battery by Introducing Graphene \& Lead Composite

(pp. $1-12$ )

Theses graph shows how much a current is gained at a specific range of voltage. Fig. 5, is analyzed that the current conduction of this specimen-01 is low as compare to other specimens which shows that graphene and lead

are not mixed properly because at same applied voltage current varies and comparatively to other specimens, its charge rate is slow that it requires more voltage for same conduction of current.

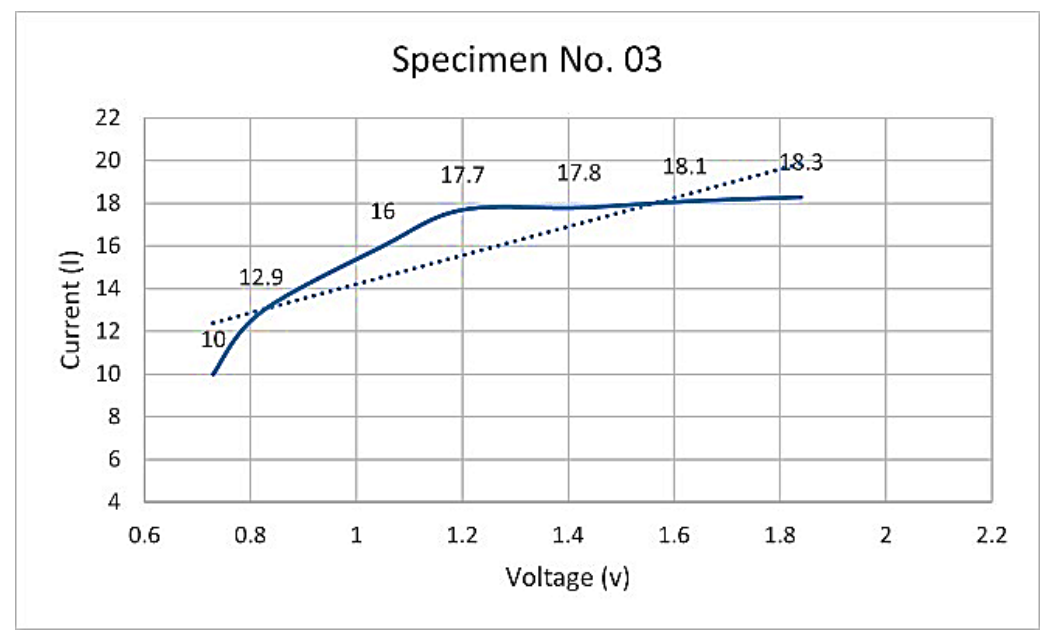

Fig. 7.the composition of graphene material is $1.5 \%$ and lead is $98.50 \%$.

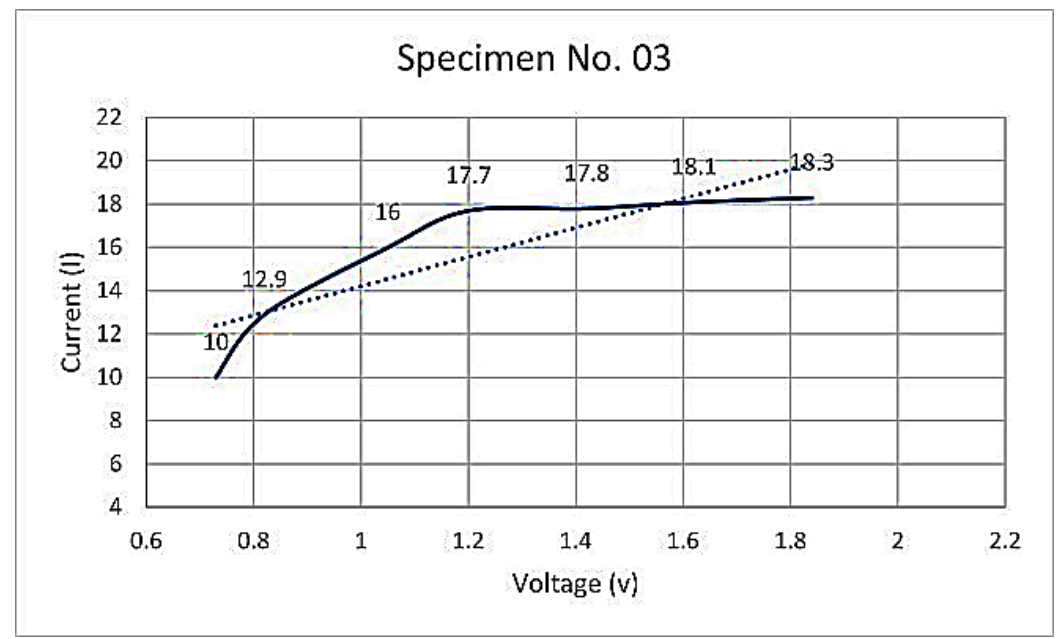

Fig. 8. The composition of graphene material is $0.5 \%$ and lead is $99.5 \%$. 
In Fig. 6, the composition of graphene material is $1.0 \%$ and lead is $99.0 \%$. it is analyzed that applied voltages current conduction is less than specimen-01. In Fig. 7, the composition of graphene material is $1.5 \%$ and lead is $98.5 \%$. The specimen-03 can conduct maximum amount of current at peak amount of voltage and remains constant at that range of voltage, which shows that graphene and lead can withstand high current density. In Fig. 8, the composition of graphene material is $2.0 \%$ and lead is $98.0 \%$. it is analyzed that the current conduction of specimen-04 is low as compare to other specimens, which shows that graphene and lead are not mixed properly because at same applied voltage current varies and comparatively to other specimens, its charge rate is slow that it requires more voltage for same conduction of current.

\subsection{Scanning electron microscopy test}

The technique was instated with the smooth cutting of center chips and their mounting test stub, utilizing a conductive twofold sided-carbon arrangement tape. The primary and secondary that is anodic and cathodic motion of electrons forms bright images of specimen. Scanning electron microscopy test of every specimen is carried out at 100 zoom extent and applied 20KV.

In Fig. 9(a), the specimen no. 1 shows that primary electrons which only passes from lead and very little from graphene whereas secondary electrons are scattered around the surface. The grey color shows the concentration of lead and graphene whereas black shows the void or unmixed material.

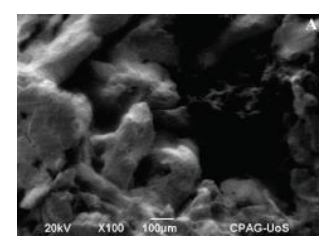

(a)

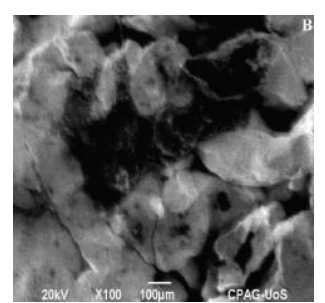

(b)

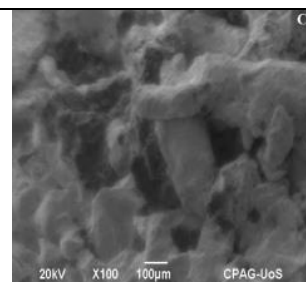

(c)

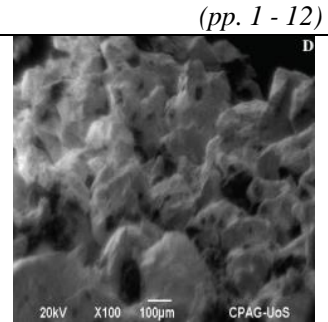

(d)
Fig. 9. Microstructure test of Specimens at 500x magnification.

Those electrons which pass from the specimen shows the materials are properly mixed and conduction of charges will be continuous at these points. Fig. 9(a) is electronic image and shows that the material in specimen no. 1 is making bulk instead of making granular structure at the center of sample which leads to the breakage of specimen by applying continues amount of force or by sudden high voltage. In Fig. 9(b), the specimen no. 2 shows that most of the material is properly mixed and primary electrons passed through it whereas at the upper side of sample voids are appeared, which shows that electrons cannot pass through this area. This sample can easily diffuse when it reacts with acids. In Fig. 9(c), the specimen no. 3 , it is noted that both materials are mixed properly, and no voids are appeared. This shows all the electrons are passed from the specimen and the whole sample can conduct current at every point of it. In Fig. 9(d), specimen no. 4 shows that the upper corners of this sample are not mixed properly, and electrons scattered back and there are some other voids in center of sample. Fig. 9(d) shows that flow of charges at any point will not be continued.

\subsection{Energy dispersive X-Ray spectrometer test}

Energy dispersive X-ray spectroscopy test is conducted to identify and quantify the elemental compositions in developed specimens. From Fig. 10, it is noted that less amount of graphene is mixed and $0.5 \%$ of graphene is used specimen no. 01. Because of minimum amount of graphene additives are less. Only oxygen is present in this specimen. 


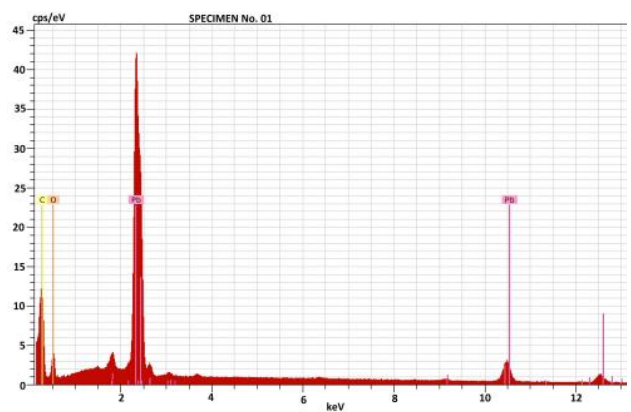

Fig. 10. Energy dispersive X-Ray spectrometer test of specimen No. 01.

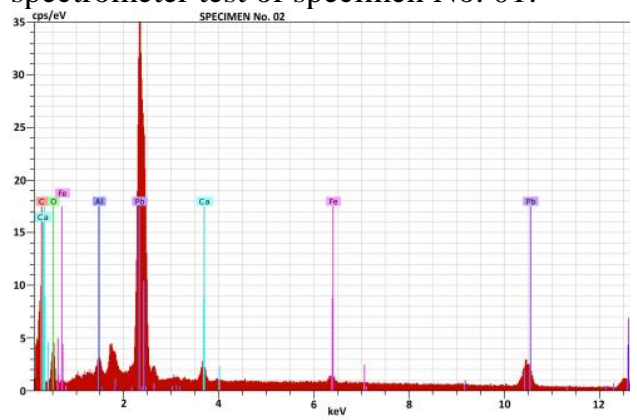

Fig. 11. Energy dispersive X-Ray spectrometer test of specimen No. 02 .

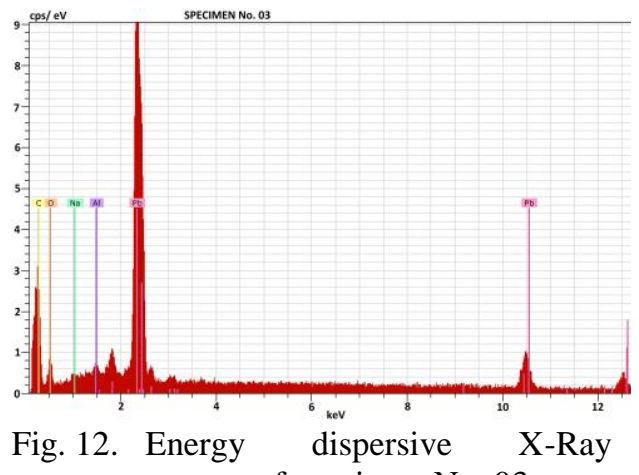
spectrometer test of specimen No. 03.

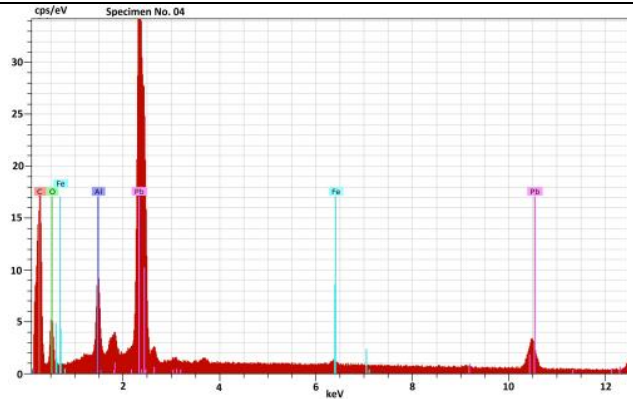

Fig. 13. Energy dispersive X-Ray spectrometer test of specimen No. 04.

Fig. 11, for specimen no. 02 , where $1 \%$ of graphene is used. It is analyzed that different materials are found such as aluminum, iron etc. These additive materials can damage the composition and can react with acid. Fig. 12 is for specimen no. 03 , where $1.5 \%$ of graphene is used and from the graph, equal amount of other crystalline materials is found. These additives are not reacting with lead but can easily react with acid and can generate the gaseous issues. From Fig. 13 is clearly shown that graphene is not mixed properly with lead and because of excess amount of graphene additives are present at high rate. It can damage sample easily and cannot be used for more cycles. From all these figures, it can be identified that in these material lead and graphene have some unknown crystalline additives are added which are present in every sample. These materials include carbon, iron, calcium, aluminum etc. they may be because of testing equipment or might be because of carbon in graphene. But all these additive materials are at very short amount in each sample which may not damage the sample mixture.

\subsection{Corrosion test}

This test for the internal protection of the battery. In these test Tafel plots are generated between the log current and potential which shows the how much log current resist at the different voltage. This is done by putting a sample in $25 \%$ of dilute sulfuric acid with three electrodes terminal then dip in the container 
Muhammad Atif Qaimkhani (et al.), Experimental Analysis of Lead Acid Battery by Introducing Graphene \& Lead Composite

and run the program on computer then plots are generated automatically.
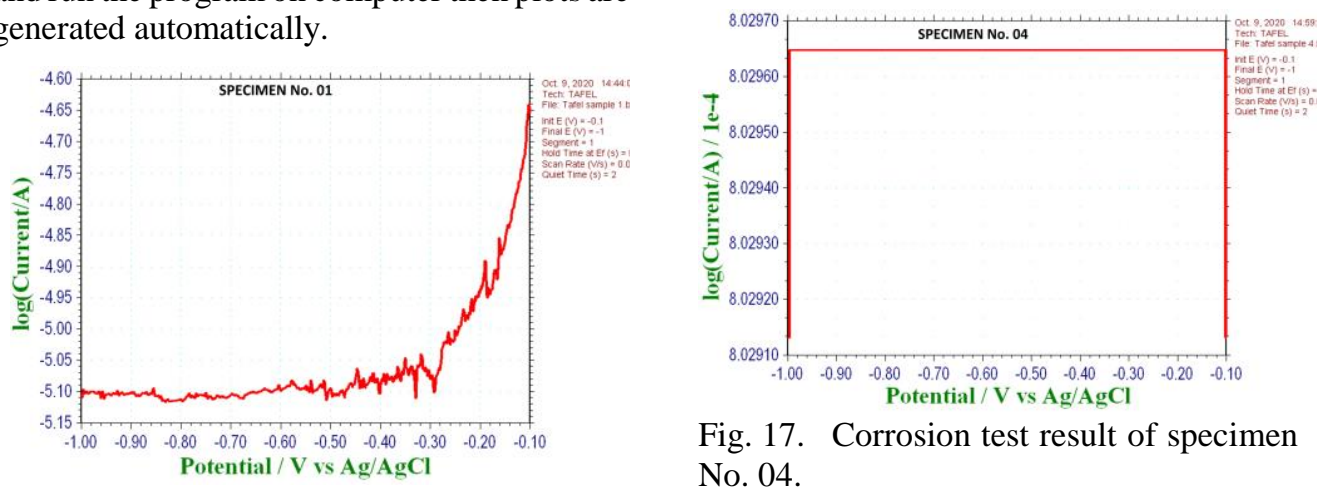

Fig. 17. Corrosion test result of specimen

Fig. 14. Corrosion test result of specimen No. 01.

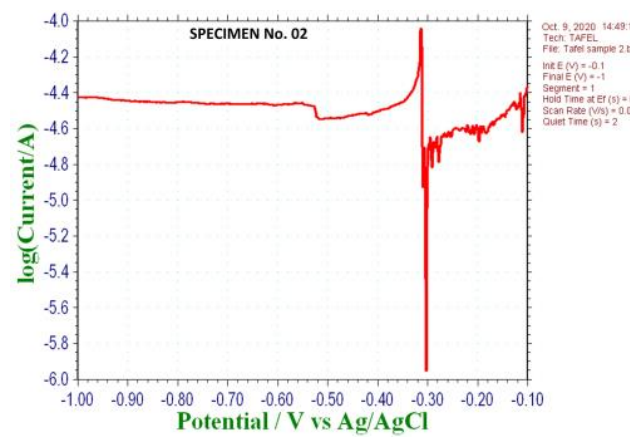

Fig. 15. Corrosion test result of specimen No. 02.

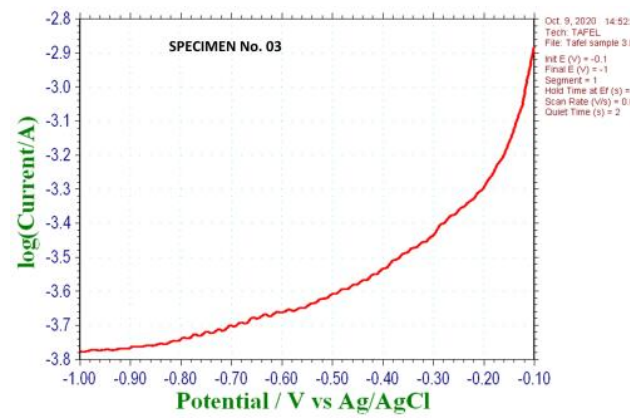

Fig. 16. Corrosion test result of specimen No. 03. No. 04.

Fig. 14 for specimen no. 01 shows that with the less amount of voltage and current, corrosion increases. Here graphene is diluting in acid rapidly it is not mixed properly. Fig. 15 for specimen no. 02 shows that decrease in voltage and current are not affecting on corrosion, it remains constant. That means by this concentration of specimen no. 02 constant dilution of materials in acid occurs. Fig. 16 for specimen no. 03 shows that at very amount of current and voltage, minimum corrosion occurs, which means that both materials are mixed properly, and less amount of material can be transmitted in acid and less corrosion occurs. Fig. 17 for specimen no. 03 shows that high amount of corrosion occurs at constant rate, at each cycle material will be transmitted in acid at large quantity.

\subsection{Impedance Spectra test}

This test is based on computer software and plots are generated between the log ohm and potential. This is done by putting specimens in $25 \%$ of dilute sulfuric acid with three electrodes terminal then dip in the container and run the program to generate the plots. If the value of impedance is a smaller amount, then it will accommodate fast charge and charge capacity will have increased.

Fig. 18 for specimen no. 1 shows that at the range of $0.8 \mathrm{~V}$ to $2.2 \mathrm{~V}$ maximum current that is $3.3 \mathrm{Z} / \mathrm{Ohm}$ have achieved but that will not be efficient because at very minimum voltage range such quantity of current can generate heat. Fig. 19 for specimen no. 2 shows that at voltage ranges $0.8 \mathrm{~V}$ to $2.2 \mathrm{~V}$ less amount of 
Muhammad Atif Qaimkhani (et al.), Experimental Analysis of Lead Acid Battery by Introducing Graphene \& Lead Composite

current is conducted, which means materials are not properly mixed. Because of low conductivity of charges, it causes great amount of corrosion. Fig. 20 for specimen no. 3 shows that it is analyzed that at range of $0.8 \mathrm{~V}$ to $2.2 \mathrm{~V}$ peak amount of current is conducted. The specimen no. 3 is efficient to use because there will be less chances of corrosion. Fig. 21 for specimen no. 4 shows that it can conduct good rate of charge but because of fluctuations it can break easily at very low voltage range.

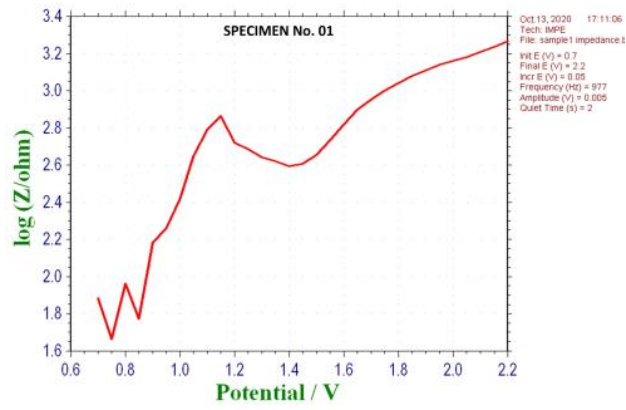

Fig. 18. Impedance spectra test result of specimen No. 01.

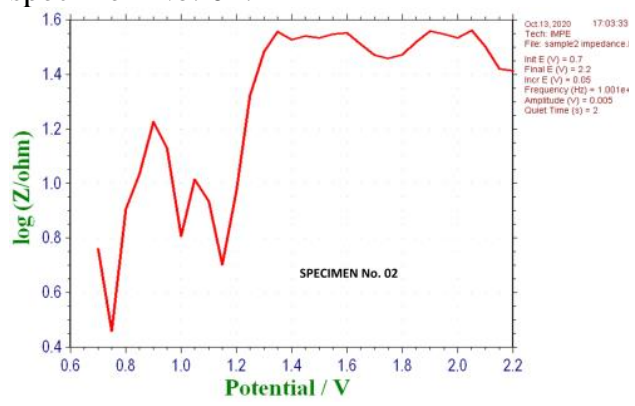

Fig. 19. Impedance spectra test result of specimen No. 02.

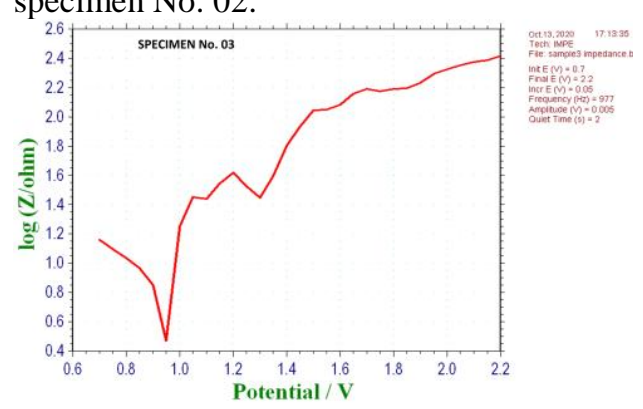

Fig. 20. Impedance spectra test result of specimen No. 03.

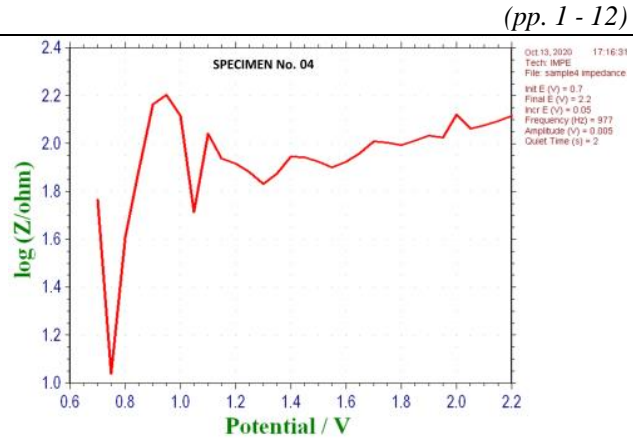

Fig. 21. Impedance spectra test result of specimen No. 04.

\subsection{X-Ray diffraction test}

$\mathrm{X}$-beam powder diffraction is a fastexpository method mainly developed for stage distinguishing proof of a crystalline-material and can give data at unit-cell measurements. Fig. 22 shows bulk analytical composition of all specimens. The maximum peak of lead is lying in between the 30-40 degree of all specimens. Although we can define the material which is present in all specimens based on energy dispersive $\mathrm{x}$-ray spectrometer.

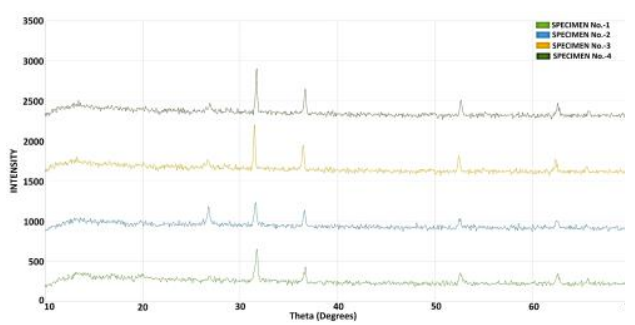

Fig. 22. XRD test results of all specimens.

\subsection{Cyclic voltammetry (CV) test}

This technique is used to measure the current that develops in an electrochemical cell under conditions where voltage is more than that predicted by the Nernst equation. Cyclic voltammetry test is performed by cycling the potential of a working electrode, and measuring the resulting current is performed by cycling the capability of a working cathode and estimating the subsequent current. Fig. 23 shows that at 10 repeating cycle, voltage ranges from $0.6 \mathrm{~V}$ to $2.2 \mathrm{~V}$ and current $9.80 \mathrm{~A}$. It shows that every cycle there is chances of breakage of material or dispatching can occur at very low quantity. Fig. 24 shows that that at 
Muhammad Atif Qaimkhani (et al.), Experimental Analysis of Lead Acid Battery by Introducing Graphene \& Lead Composite

10 cycles there is no any point of breakage and constant amount of reduction from material occur at same voltage range and current. Fig. 25 shows that at same voltage range and current constant amount of reduction occurs that is with increase in current at maximum level constant dissipating occurs. It will decrease the life span of specimen. Fig. 26 shows that at same voltage range it conducts very low current and constant reduction of material in each cycle occurs.

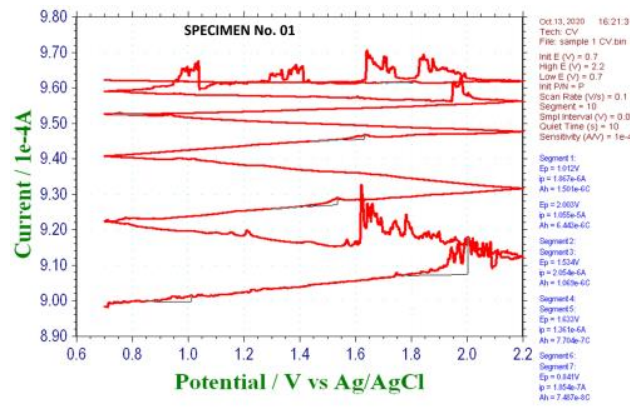

Fig. 23. CV test result of specimen No. 01.

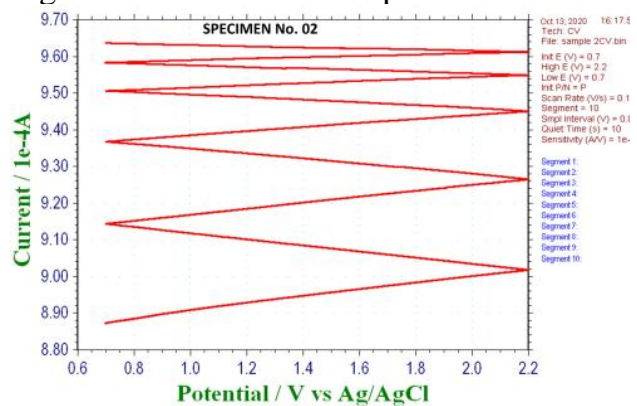

Fig. 24. CV test result of specimen No. 02 .
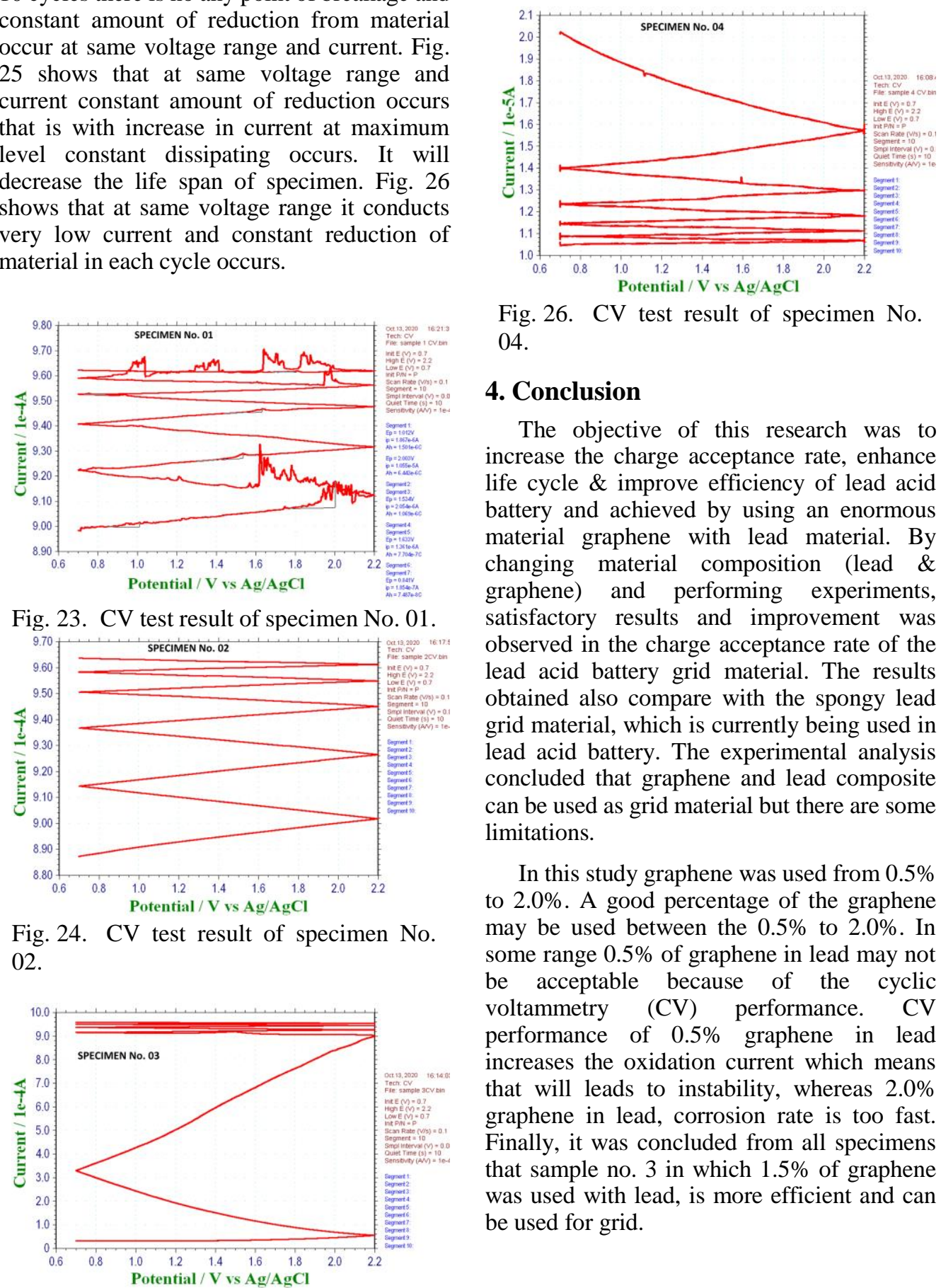

Fig. 26. CV test result of specimen No. 04.

\section{Conclusion}

The objective of this research was to increase the charge acceptance rate, enhance life cycle \& improve efficiency of lead acid battery and achieved by using an enormous material graphene with lead material. By changing material composition (lead \& graphene) and performing experiments, satisfactory results and improvement was observed in the charge acceptance rate of the lead acid battery grid material. The results obtained also compare with the spongy lead grid material, which is currently being used in lead acid battery. The experimental analysis concluded that graphene and lead composite can be used as grid material but there are some limitations.

In this study graphene was used from $0.5 \%$ to $2.0 \%$. A good percentage of the graphene may be used between the $0.5 \%$ to $2.0 \%$. In some range $0.5 \%$ of graphene in lead may not be acceptable because of the cyclic voltammetry (CV) performance. CV performance of $0.5 \%$ graphene in lead increases the oxidation current which means that will leads to instability, whereas $2.0 \%$ graphene in lead, corrosion rate is too fast. Finally, it was concluded from all specimens that sample no. 3 in which $1.5 \%$ of graphene was used with lead, is more efficient and can be used for grid.

Fig. 25. CV test result of specimen No. 03 . 


\section{References}

[1] Xin, G., et al., Large-area freestanding graphene paper for superior thermal management. Advanced materials, 2014. 26(26): p. 4521-4526.

[2] Xiang, J. and L.T. Drzal, Electron and phonon transport in $\mathrm{Au}$ nanoparticle decorated graphene nanoplatelet nanostructured paper. ACS applied materials \& interfaces, 2011. 3(4): p. 1325-1332.

[3] Dong, C., Comment on" Advanced mechanical properties of graphene paper". Journal of Applied Physics, 2012. 111: p. 106101-106101.

[4] Huang, X., X.Y. Qi, and F. Boey, Zhang. H. Graphene-based composites. Chem. Soc. Rev, 2012. 41: p. 666-686.

[5] Huang, W., X. Ouyang, and L.J. Lee, ACS Nano 6, 10178 (2012). Crossref, ISI.

[6] Bollen, M.H.J. and F. Hassan, Integration of distributed generation in the power system. Vol. 80. 2011: John wiley \& sons.

[7] Dell, R. and D.A.J. Rand, Understanding batteries. 2001: Royal society of chemistry.

[8] Pavlov, D. and L.-A. Batteries, Science and Technology: A Handbook of Lead-Acid Battery Technology and Its Influence on the Product. 2017, Elsevier.

[9] Julien, C., et al., Lithium batteries, in Lithium Batteries. 2016, Springer. p. 29-68.

[10] Chen, A. and P.K. Sen. Advancement in battery technology: A state-of-the-art review. IEEE.

[11] Alamgir, M., Lithium has transformed vehicle technology: How trends in li-ion battery technology have developed for vehicle electrification. IEEE Electrification Magazine, 2017. 5(1): p. 43-52.
[12] Abd El-Rahman, H.A., S.A. Salih, and A.M. Abd El-Wahab, Effect of Phosphoric Acid on the Electronic and Diffusion Proper-ties of the Anodic Passive Layer Formed on Pb-1.7\% Sb Grid of Lead-acid Batteries. Journal of Electrochemical Science and Technology, 2011. 2(2): p. 76-84.

[13] Voss, E., Effects of phosphoric acid additions on the behaviour of the lead-acid cell: A review. Journal of power sources, 1988. 24(3): p. 171-184.

[14] Meissner, E., Phosphoric acid as an electrolyte additive for lead/acid batteries in electricvehicle applications. Journal of power sources, 1997. 67(1-2): p. 135-150.

[15] Sternberg, S., V. Branzoi, and L. Apateanu, Study of electrode processes in $\mathrm{Pb} / \mathrm{H} 2 \mathrm{SO} 4+$ additive systems. Journal of power sources, 1990. 30(1-4): p. 177-183.

[16] Sternberg, S., et al., Effect of H3PO4 on the $\mathrm{PbSO} 4 / \mathrm{PbO} 2$ electrode in $\mathrm{H} 2 \mathrm{SO} 4$ solutions. Electrochimica acta, 1987. 32(2): p. 349-351.

[17] Yazd, M.S., A. Molazemi, and M.H. Moayed, The effects of different additives in electrolyte of AGM batteries on self-discharge. Journal of power sources, 2006. 158(1): p. 705-709.

[18] Watson, H., Storage battery maintenance and principles. Facilities instructions, standards, and techniques. Volume 3-6. 1991, Bureau of Reclamation, Denver, CO (United States). Engineering Div.

[19] Schilling, S., Ensuring lead-acid battery performance with pulse technology. SAE transactions, 2003: p. 360-364.

[20] Lam, L.T., et al., Pulsed-current charging of lead/acid batteries - a possible means for overcoming premature capacity loss? Journal of Power Sources, 1995. 53(2): p. 215-228.

[21] Jamali, A. H., Samo, S., Shaikh, S. A., Hussain, T. and Qaimkhani, M. A.. Analytical Analysis and Performance Characterization of Hexagonal Grid Configuration of Wet Cell Battery. International Journal on Emerging Technologies, 2020, 11(5): 459-464. 